\title{
INTERNATIONAL BIBLIOGRAPHY OF REINSURANCE
}

\author{
4TH EDition, $1979 / 80$
}

Publisher and Copyright: Bayerische Rückversicherung Aktiengesellschaft, Sederanger 4-6, Tucherpark, 8000 Munich 22. F. R. of Germany.

Bavarian Re has been publishing its International Bibliography of Reinsurance (IBR) since 1962, and with it has created a highly respected aid to orientation over a significant field of international insurance literature.

The fourth edition of this standard work, which is consulted frequently by both practical and research workers, lists more than 3,200 publications from some 1,300 authors and 30 countries on matters concerning reinsurance.

The new format introduced in the $1977 / 78$ edition has been retained. User response has shown that the clearer arrangement, restructured organization, quick-reference outline and typographical reading aids have served to attain the rapid, selective access and the overall ease of use which we sought to achieve. The $1977 / 78$ edition of the IBR was recognized with an award for graphics and typography at the 1978 International Publications Competition in Berlin.

Bavarian Re intends to re-issue this work of reference in a completely revised form every two years from now on, incorporating publications which have appeared in the intervening period. 